\title{
SEMINAR FORMULASI SEDIAAN PASTA GIGI EKSTRAK DAUN PANDAN WANGI (Pandanus amaryllifolius Roxb) DAN UJI EFEKTIVITAS TERHADAP BAKTERI Streptococcus mutans
}

\author{
Asvia Rahayu' ${ }^{*}$, Sa'adah Siregar', Jhoti Sumitra², Annisa Paradita ${ }^{3}$ \\ ${ }^{1}$ Program Studi Teknologi Laboratorium Medik, Institut Kesehatan Medistra Lubuk Pakam \\ ${ }^{2}$ Program Studi Farmasi, Institut Kesehatan Medistra Lubuk Pakam \\ JIn. Sudirman No. 38 Lubuk Pakam Kabupaten Deli Serdang, \\ Sumatera Utara - Indonesia \\ *email korespondensi author : asviarahayu@gmail.com \\ DOI: $10.35451 / j p k . v 1 i 1.654$
}

\begin{abstract}
Abstrak
Daun pandan wangi (Pandanus amaryllifolius Roxb.) merupakan satu-satunya jenis tanaman dari suku Pandanaceae yang mempunyai daun beraroma wangi. Penelitian ini bertujuan untuk mengetahui apakah ekstrak daun pandan wangi. dapat diformulasikan menjadi sediaan gel pasta gigi yang stabil serta memiliki penyebab plak gigi. Bahan uji yang digunakan ekstrak daun pandan wangi untuk konsentrasi $2 \%$, 3\% dan 5\%. Hasil dari evaluasi sediaan berupa uji organoleptis, homogenitas, $\mathrm{pH}$, uji daya sebar, uji daya lekat, viskositas dan frezee-thaw cycling tiap masingmasing formula tidak mengalami perubahan yang signifikan dari minggu 0 sampai minggu ke-3 yang menandakan sediaan memiliki stabilitas yang baik. Data diperoleh dengan hasil yang menandakan adanya perbedaan yang signifikan antara formula 1, formula 2 dan formula 3. Perlu dilakukannya pembuatan formulasi dengan menggunakan zat aktif dari partisi ekstrak daun pandan wangi (Pandanus amaryllifolius Roxb.)
\end{abstract}

Kata kunci : Daun pandan wangi, ekstrak, gel pasta gigi, plak gigi.

\begin{abstract}
Fragrant pandan leaves (Pandanus amaryllifolius Roxb.) are the only plant species from the Pandanaceae tribe that have fragrant leaves. This study aims to determine whether pandan leaf extract is fragrant. can be formulated into a toothpaste gel preparation that is stable and has the cause of dental plaque. The test material used fragrant pandan leaf extract for concentrations of $2 \%, 3 \%$ and $5 \%$. The results of the evaluation of the preparations in the form of organoleptic tests, homogeneity, $\mathrm{pH}$, dispersibility tests, adhesion tests, viscosity and freeze-thaw cycling of each formula did not experience significant changes from week 0 to week 3 which indicated the preparation had good stability. good. The data obtained with results that indicate a significant difference between formula 1, formula 2 and formula 3. It is necessary to make a formulation using active substances from the partition of fragrant pandan leaf extract (Pandanus amaryllifolius Roxb.)
\end{abstract}

Keywords: Fragrant pandan leaves, extract, toothpaste gel, dental plaque. 


\section{Pendahuluan}

\subsection{Latar Belakang}

Kasus kesehatan gigi serta mulut, terus menjadi banyak bersamaan pertumbuhan era. Munculnya penyakit gigi serta mulut dipengaruhi sebagian aspek ialah, status sosial, ekonomi, pola makan, dan budaya dari warga.

Kebutuhan buat mensterilkan gigi setara dengan kepentingan buat mebersihkan badan, cocok dengan pertumbuhan pola makan warga saat ini dengan banyaknya bermunculan bermacam santapan olahan, hingga peluang terbentuknya kehancuran gigi pula hendak terus menjadi meningkat. Kehancuran gigi bisa diakibatkan oleh zat santapan, paling utama yang memiliki karbohidrat yang tertinggal serta menempel pada bagian serta sela gigi. Karohidrat ialah substrat yang digunakan oleh kuman buat mensintesa asam serta polisakarida ekstrasel sehingga bisa membentuk plak pada gigi( Akmal, 2014).

Rongga mulut ialah pintu gerbang masuknya santapan kedalam badan manusia. Oleh sebab itu rongga mulut memainkan peranan yang sangat berarti dalam melindungi kesehatan badan secara totalitas. Dalam rongga mulut ada bermacam tipe mikroorganisme antara lain merupakan Streptococcus, Staphylococcus, serta sebagian mikrokokus berpigmen yang terkategori mikroflora wajar. Streptococcus mutans ialah kuman gr positif berupa bundar yang secara khas membentuk pendamping ataupun rantai sepanjang masa pertumbuhannya. Kuman ini tersebar luas dialam, sebagian antara lain ialah anggota flora wajar pada manusia, yang lain dihubungkan dengan penyakit- penyakit berarti( Nurin, 2012).

Salah satu metode buat menghindari terbentuknya permasalahan kesehatan gigi serta mulut merupakan dengan menggosok gigi. Menggosok gigi memakai pasta gigi bisa menolong menghindari terbentuknya penyakit gigi serta mulut dan membuat gigi senantiasa kokoh( Nurin, 2012).

Pasta gigi yang digunakan pada dikala menggosok gigi pula berperan buat kurangi pembuatan plak, menguatkan gigi terhadap karies, mensterilkan serta memoles permukaan gigi, melenyapkan ataupun kurangi bau mulut, membagikan rasa fresh pada mulut dan memelihara kesehatan gigi. Menggosok gigi memakai pasta gigi disarankan 2 kali satu hari ialah setelah makan serta saat sebelum tidur( Nurin, 2012).

Pasta gigi mengandung berbagai macam bahan kimia, salah satunya adalah flouride. Floride yang terkandung dalam pasta gigi berkaitan dengan pencegahan terhadap terbentuknya karies gigi, penggunaan flourida dalam jumlah besar selama kurun waktu tertentu dapat menimbulkan efek samping, yaitu terjadinya bintik bintik pada email gigi (Nurin, 2012).

Indonesia sebagai negara tropis memiliki keanekaragaman sumber daya alam hayati. Terutama dengan banyaknya spesies obat. Salah satu tanaman yang diduga memiliki khasiat antimikroba adalah pandan wangi (Pandanus amaryllofolius Roxb) Sejak dahulu tumbuhan ini digunakan sebagai obat tradisional, yaitu sebagai anti ketombe, lemah saraf, sebagai antidiabetik, antioksidan, analgesik, antibakteri, pewangi dan pewarna makanan, senyawa yang diketahui terkandung dalam pandan wangi adalah senyawa fenolik, alkaloid, flavonoid, saponin, tanin, minyak atsiri dan terpenoid tetapi data ilmiah tentang khasiat tanaman pandan wangi masih sedikit (Aisyah, 2015).

Pandan wangi

(Pandanus amaryllofolius Roxb) memiliki khasiat 
sebagai antibakteri karena kandungan zat kimia dari daun pandan wangi seperti alkaloid, saponin, flavonoid, tanin, polifenol dan steroid merupakan senyawa metabolit sekunder pada tumbuhan yang bersifat antibakteri (Yoan, 2015).

Peneliti sebelumnya yaitu (Oom komala, Putri dan Dwi, 2017). telah memformulasikan daun pandan wangi (Pandanus amaryllifolius Roxb) dalam sediaan mouthwash, maka penulis tertarik untuk memformulasi daun pandan wangi dalam sediaan pasta gigi dan melakukan pengujian efektivitas terhadap bakteri Streptococcus mutans. Aplikasi daun pandan wangi diharapkan dapat sebagai alternatif bahan antibakteri yang ada dalam formulasi pasta gigi.

\subsection{Tujuan Penelitian}

\subsubsection{Tujuan Umum}

Untuk mengetahui apakah pasta gigi ekstrak daun pandan wangi (Pandanus amaryllifolius Roxb) berpengaruh terhadap daya hambat bakteri Streptococcus mutans?

\subsubsection{Tujuan Khusus}

a. Untuk mengetahui apakah ekstrak daun pandan wangi (Pandanus amaryllifolius Roxb) dapat diformulasikan dalam sediaan pasta gigi

b. Untuk mengetahui sifat fisik dan stabilitas pasta gigi ekstrak daun pandan wangi (Pandanus amaryllifolius Roxb)

c. Untuk mengetahui daya hambat pasta gigi ekstrak daun pandan wangi (Pandanus amaryllifolius Roxb) terhadap bakteri Streptococcus mutans pada konsentrasi $15 \%$, 20\%, 25\%

d. Untuk mengetahui konsentrasi terbaik dari pasta gigi ekstrak daun pandan wangi (Pandanus amaryllifolius Roxb) terhadap daya hambat bakteri Streptococcus mutans

\section{Metode}

\subsection{Metode Penelitian}

Jenis penelitian ini adalah penelitian eksperimental untuk mengetahui daya hambat bakteri ekstrak daun pandan wangi (Pandanus amaryllifolius Roxb.) setelah diformulasikan kedalam sediaan Pasta gigi. Pada metode ini meliputi pengumpulan dan identifikasi bahan tumbuhan, pembuatan simplisia, skrining fitokimia, pembuatan ekstrak dari simplisia secara maserasi, serta pengujian antibakteri ekstrak daun pandan wangi (Pandanus amaryllifolius Roxb) dengan metode difusi menggunakan kertas cakram. Parameter yang diambil adalah besarnya diameter hambat pertumbuhan bakteri.

\subsection{Hipotesis}

Hipotesis merupakan jawaban sementara terhadap rumusan masalah penelitian, belum jawaban yang empiric dengan data. Hipotesis penelitian ini adalah:

1. Ekstrak daun pandan wangi(Pandanus amaryllifolius Roxb) dapat diformulasikan dalam sediaan pasta gigi

2. Sediaan pasta gigi ekstrak daun pandan wangi (Pandanus amaryllifolius Roxb) dapat menghambat bakteri Streptococcus mutans

\subsection{Tempat Dan Waktu Pelaksanaan} Penelitian

Penelitian ini dilakukan di Laboratorium Farmasetika, Laboratorium Kimia Organik, dan Laboratorium Sterilisasi Fakultas Farmasi Institut Kesehatan Medistra Lubuk Pakam. dan dilaksanakan pada bulan April - Mei 2019. 


\subsection{Alat Dan Bahan}

\subsubsection{Alat}

Alat yang digunakan dalam penelitian ini adalah alat-alat gelas (Pyrex), Autoclave, Batang Pengaduk, Bejana Maserasi, Blender, Bunsen, Cawan petri, Cawan Porselin, Cover glass, Hot plate, Inkubator, Jarum ose, Kertas Perkamen, Laminar air flow, Lumpang dan alu, Neraca analitik, Oven, Penggaris, Pipet Mikro, Pipet tetes, $\mathrm{pH}$ meter, Vacuum rotary evaporator, Sendok tandu .k, Wadah pasta gigi.

\subsubsection{Bahan}

Bahan yang digunakan dalam penelitian ini adalah Aquadest, Bakteri Streptococcus mutans, Daun Pandan wangi (Pandanus amaryllifolius Roxb),Dimetylsulfoksida (DMSO), Etanol 96\%, Gliserin, Kapas steril, Kalsium karbonat, Menthol, Natrium benzoat, Natrium lauryl sulfat, Natrium Carboxymethyl Cellulose, Natrium sakarin, $\mathrm{NaCl} 0,9 \%$, Nutrient Agar (NA), Natrium Broth (NB), Tube pasta gigi.

\subsection{Penyiapan Sampel}

\subsubsection{Pengambilan Sampel}

Pengumpulan sampel dilakukan secara random sampling, yaitu secara acak tanpa membandingkan dengan daerah lain. Sampel yang digunakan adalah Daun pandan wangi (Pandanus amaryllifolius $R o x b$ ) yang diperoleh dari Desa Sekip Kecamatan Lubuk Pakam, Kabupaten Deliserdang, Provinsi Sumatera Utara.

\subsubsection{Pengolahan Sampel}

Sampel daun pandan wangi (Pandanus amaryllifolius Roxb) Segar yang digunakan dikumpulkan Sebanyak $7 \mathrm{Kg}$, dan selanjutnya dilakukan sortasi basah lalu dicuci bersih dengan air mengalir. Daun pandan yang telah dibersihkan dirajang dan kemudian dikeringkan. Simplisia yang telah kering di sortasi kering dan dijadikan serbuk dengan cara di blender dan diayak.
Serbuk simplisia disimpan dalam wadah bersih dan tertutup rapat.

\subsection{Skrining Fitokimia}

Skrining fitokimia serbuk simplisia Daun pandan wangi (Pandanus amaryllifolius Roxb.) meliputi pemeriksaan senyawa golongan alkaloid, saponin, flavonoid, tanin.

\subsubsection{Pembuatan Larutan Pereaksi}

Menurut Retno 2017, pembuatan suatu larutan pereaksi sebagai berikut:

1. Pereaksi asam klorida $2 \mathrm{~N}$

Sebanyak 16, $67 \mathrm{ml}$ asam klorida pekat dilarutkan dalam air suling sampai volume $100 \mathrm{ml}$.

2. Pereaksi asam sulfat $2 \mathrm{~N}$

Sebanyak 5, $4 \mathrm{ml}$ asam sulfat pekat dilarutkan dalam air suling sampai volume $100 \mathrm{ml}$.

3. Pereaksi Meyer

Sebanyak 1, 35 gram raksa( II)

klorida dilarutkan dalam $60 \mathrm{ml}$ air suling. Setelah itu pada wadah lain sebanyak 5 gram kalium iodide dilarutkan dalam 10 mlair kemudian gabungkan keduanya serta ditambahkan air suling sampai $100 \mathrm{ml}$.

4. Peraksi Bouchardat

Sebanyak 1, 35 gram kalium iodide, dilarutkan dalam sedikit air suling setelah itu ditambahkan 2 gram iodium, sehabis seluruhnya larut ditambahkan air suling sampai $100 \mathrm{ml}$.

5. Pereaksi Dragendroff

Sebanyak 0, 85 gram Bismut( III) nitrat ditimbang, setelah itu dilarutkan dalam $100 \mathrm{ml}$ asam asetat glacial ditambahkan $40 \mathrm{ml}$ air suling. Setelah itu pada wadah kemudian ditimbang 8 gram kalium iodide kemudian dilarutkan dalam $20 \mathrm{ml}$ air suling, kemudian gabungkan kedua larutan sama banyak. Setelah itu ditambahkan $20 \mathrm{ml}$ asam asetat glasial serta diencerkan air suling sampai 100 $\mathrm{ml}$.

5. Pereaksi Timbal( II) Asetat 0, $4 \mathrm{M}$ Sebanyak 8, 002 gram Kristal natrium hidroksida dilarutkan dalam air suling sampai $100 \mathrm{ml}$. 


\subsubsection{Pengecekan Senyawa Kimia}

1. Pengecekan Alkaloid

Sebanyak 0, 5 gram Serbuk daun pandan wangi dimasukkan kedalam tabung respon setelah itu ditambahkan $1 \mathrm{ml}$ asam klorida $2 \mathrm{~N}$ serta $9 \mathrm{ml}$ air suling, dipanaskan diatas penangas air sepanjang 2 menit, didinginkan serta disaring. Filtrate yang diperoleh dipakai buat uji alkaloida: diambil 3 tabung respon, kemudian kedalamnya dimasukkan 0, $5 \mathrm{ml}$ filtrate. Pada masing masing tabung respon:

a. Ditambahkan 2 tetes pereaksi mayer

b. Ditambahkan 2 tetes pereaksi Bouchardat

c. Ditambahkan 2 tetes pereaksi Dragendroff

alkaloida positif bila terjalin endapan ataupun kekeruhan pada sangat sedikit 2 dari 3 percobaan di atas( Depkes, 1995).

2. Pengecekan Saponin

Sebanyak 0, $5 \mathrm{~g}$ Serbuk Daun pandan wangi dimasukka kedalam tabung respon, kemudian ditambahkan $10 \mathrm{ml}$ air panas, didinginkan setelah itu dikocok kuat- kuat sepanjang 10 detik. Bila tercipta busa setinggi 1- 10 centimeter yang normal tidak kurang dari 10 menit serta tidak lenyap dengan akumulasi 1 tetes asam klorida $2 \mathrm{~N}$ menampilkan terdapatnya saponin( Depkes, 1995).

3. Pemeriksaan Flavonoid

Sebanyak $10 \mathrm{~g}$ Serbuk simplisia daun pandan wangi ditambahkan $10 \mathrm{ml}$ air panas, dididihkan selama 5 menit dan disaring dalam keadaan panas.kedalam $5 \mathrm{ml}$ filtrate ditambahkan $0,1 \mathrm{~g}$ serbuk magnesium dan $1 \mathrm{ml}$ asam klorida pekat dan $2 \mathrm{ml}$ alcohol dan dibiarkan memisah. Flavonoid positif jika warna merah atau kuning jingga pada lapisan amil alkohol (Erma, 2019)

4. Pemeriksaan Tanin

Sebanyak 0,5 g Serbuk simplisia daun pandan wangi disari dengan $10 \mathrm{ml}$ air suling. Lalu disaring filtratnya diencerkan dengan air sampai tidak berwarna. Larutan diambil sebanyak 2 $\mathrm{ml}$ dan ditambahkan 1-2 tetes pereaksi besi (III) klorida $1 \%$ jika terjadi warna biru atau kehitaman menunjukkan adanya tanin (Retno, 2017).

\subsection{Pembuatan Ekstrak Daun Pandan Wangi}

Serbuk Simplisia Daun pandan wangi sebanyak $500 \mathrm{gr}$ di ekstraksi dengan pelarut etanol $96 \%$ menggunakan metode maserasi. Serbuk dimasukkan kedalam bejana kemudian dituangi dengan pelarut etanol $96 \%$, ditutup dan dibiarkan selama $3 \times 24$ jam pada suhu ruang sambil berulang-ulang diaduk agar zat aktif terekstraksi sempurna. Setelah 3 hari ekstrak disaring, kemudian residu di ekstraksi kembali dengan pelarut etanol. Bejana ditutup dan dibiarkan pada suh ruang dan terlindung dari cahaya selama $3 \times$ 24 jam lalu disaring. Ekstrak yang diperoleh dipekatkan dengan menggunakan vacuum rotary evaporator untuk memisahkan pelarut dengan zat aktif lalu di uapkan lagi di atas penangas air hingga diperoleh ekstrak kental daun pandan wangi. Ekstrak kemudian ditimbang untuk mengetahui berat dan persentase ekstrak.

\subsection{Formulasi Sediaan}

\subsubsection{Formulasi Sediaan Pasta Gigi}

Pasta gigi dibuat dalam 4 Formula yang dibedakan oleh konsentrasi ekstrak Daun pandan wangi. Ekstrak daun pandan wangi digunakan sebagai bahan aktif. Konsentrasi ekstrak yang digunakan untuk membuat Pasta gigi Antibakteri adalah $15 \% \quad 20 \%$ dan $25 \%$ yang ditambahkan pada masing masing formula. Sebagai blanko digunakan Pasta gigi tanpa ekstrak daun pandan wangi.

Formulasi sediaan pasta gigi dapat dilihat pada tabel 1 . 
Tabel 1. Formula Sediaan Pasta Gigi

\begin{tabular}{|c|c|c|c|c|c|}
\hline \multirow[b]{2}{*}{ Bahan (\%) } & \multirow[b]{2}{*}{ Fungsi } & \multicolumn{4}{|c|}{ Formula } \\
\hline & & F1 & F2 & F3 & F4 \\
\hline Ekstrak daun Pandan & Bahan aktif & 0 & 15 & 20 & 25 \\
\hline Kalsium karbonat & Abrasif & 45 & 45 & 45 & 45 \\
\hline Gliserin & Humektan & 25 & 25 & 25 & 25 \\
\hline $\begin{array}{l}\text { Natrium } \\
\text { karboksilmetylcellulose } \\
\text { (Na CMC) }\end{array}$ & Pengikat & 1,5 & 1,5 & 1,5 & 1,5 \\
\hline Natrium lauryl sulfat & Surfaktan & 1 & 1 & 1 & 1 \\
\hline Natrium Benzoat & Pengawet & 0,1 & 0,1 & 0,1 & 0,1 \\
\hline Natrium sakarin & Pemanis & 0,2 & 0,2 & 0,2 & 0,2 \\
\hline Menthol & Pengaroma & 0,2 & 0,2 & 0,2 & 0,2 \\
\hline Aquadest & Pelarut & Ad 100 & Ad 100 & Ad 10 & Ad 100 \\
\hline
\end{tabular}

Keterangan :

F1 : Pasta gigi tanpa ekstrak (blanko)

F2 : Pasta gigi dengan ekstrak daun pandan wangi $20 \%$

F2 : Pasta gigi dengan ekstrak daun pandan wangi $30 \%$

F3 : Pasta gigi dengan ekstrak daun pandan wangi $40 \%$

Perhitungan Konsentrasi ekstrak:

Ekstrak $(\%) \times$ Total Volume Sediaan

$15 \% \times 100 \mathrm{gr}=15 \mathrm{gr}$

$20 \% \times 100 \mathrm{gr}=20 \mathrm{gr}$

$25 \% \times 100 \mathrm{gr}=25 \mathrm{gr}$

Cara Pembuatan :

Ditimbang bahan aktif Ekstrak Daun pandan wangi dengan variasi konsentrasi $15 \%$, 20\%, dan $25 \%$ dan bahan tambahan kalsium karbonat, gliserin, natrium karboksimetilselulosa ( $\mathrm{Na} \mathrm{CMC}$ ), natrium lauryl sulfat, natrium benzoate, natrium sakarin, menthol dan aquadest. Melarutkan $\mathrm{Na}$ CMC dalam air panas didiamkan sepanjang 15 menit, sehabis itu diaduk homogen selaku massa 1 . Menggerus kalsium karbonat, serta meningkatkan natrium lauryl sulfat gerus homogen, setelah itu meningkatkannya pada massa 1 jadi kombinasi sembari digerus selaku massa 2. Melarutkan ekstrak daun pandan wangi dengan gliserin diaduk homogeny serta meningkatkan pada massa 2 sembari digerus hingga homogeny. Melarutkan natrium benzoat serta natrium sakarin kedalam sisa air serta diaduk hingga larut sempurna. Setelah itu ditambahkan pada masa 2 digerus homogen hingga tercipta massa pasta. Meningkatkan menthol kedalam massa pasta, digerus hingga homogen, setelah itu masukkan pasta kedalam tube.

\subsection{Penilaian Kualitas Raga Sediaan}

1. Pengujian organoleptis

Pengujian

organoleptis pasta gigi meliputi wujud, warna, serta aroma yang diamati secara obyektif. Pengamatan ini bertujuan buat memandang terbentuknya pergantian secara signifikan pada sediaan yang sudah terbuat.( Nur Afni, 2015).

2. Pengecekan Homogenitas

Pengecekan Homogenitas dicoba dengan metode meletakkan sediaan pasta gigi yang hendak di uji diantara 2 kaca objek serta diamati terdapat ataupun tidaknya partikel agresif yang ada dalam sediaan bila tidak terdapat partikel agresif hingga dinyatakan homogen. (Nur afni, 2015).

3. Pengujian $\mathrm{pH}$

Pengukuran $\mathrm{pH}$ dilakukan dengan menggunakan alat $\mathrm{pH}$ meter yang dicelupkan kedalam sampel pasta 
Received: 19 April 2021 :: Accepted: 16 June 2021 :: Published: 30 June 2021

gigisampai menunjukkan angka yang konstan setelah beberapa saat. Nilai pH didapatkan dari angka tersebut.

\subsection{Uji Aktivitas Antibakteri Pasta Gigi Ekstrak Daun Pandan Wangi}

\subsubsection{Sterilisasi Alat Dan Bahan}

Alat dan bahan yang digunakan dalam suatu uji aktivitas antibakteri disterilkan terlebih dahulu sebelum digunakan dalam percobaan. Alat-alat gelas seperti cawan petri, tabung reaksi, erlenmeyer, pipet volume dimasukkan kedalam oven (pemanasan kering) dan disterilkan pada suhu $170^{\circ} \mathrm{C}$ selama 1-2 jam. Alat dan bahan yang tidak tahan pemanas kering seperti media, dimasukkan dalam autoclave (pemanasan basah) pada suhu $121^{\circ} \mathrm{C}$ selama 15 menit. Jarum ose dan pinset disterilkan dengan cara dibakar dengan api bunsen (Lili,Baiq, dan Purmafitriah, 2017).

\subsubsection{Pembuatan Media}

1. Pembuatan media nutrient agar (NA)

Prosedur pembuatan nutient agar adalah melarutkan dalam nutrient agar ke dalam $250 \mathrm{ml}$ aquades kemudian dipanaskan hingga mendidih dan dituangkan dalam tabung dan disterilkan dengan autoclave $121^{\circ} \mathrm{C}$ selama 15 - 10 menit. Media yang telah steril dimasukkan ke dalam cawan petri di ruangan LAF.

2. Pembuatan media Nutrient Broth (NB)

Prosedur pembuatan nurtient broth adalah sebanyak $8 \mathrm{gr}$ serbuk nutrient broth dilarutkan dalam air suling steril sedikit demi sedikit kemudian volumenya dicukupkan hingga 1 liter.

3. Larutan Nacl 0,9\%

Komposisi: Natrium Klorida $9 \mathrm{~g}$

Air Suling ad $1000 \mathrm{ml}$

Cara pembuatan:

Natrium klorida ditimbang sebanyak $0,9 \mathrm{~g}$ lalu dilarutkan dalam air suling steril sedikit demi sedikit dalam erlenmeyer $100 \mathrm{ml}$ sampai larut dengan sempurna, disterilkan diautoklaf pada suhu $121^{\circ} \mathrm{C}$ selama 15 menit.

4. Suspensi standar Mc Farland 0,5

Komposisi : Larutan $\mathrm{BaCl}_{2} 1,175 \%$ b/v $\quad 0,5 \mathrm{~mL}$

Larutan $\mathrm{H}_{2} \mathrm{SO}_{4} 1 \% \quad 99,5 \mathrm{~mL}$

Cara pembuatan :

Kedua larutan dicampurkan dalam tabung reaksi steril, dikocok homogen dan ditutup. Apabila kekeruhan hasil suspensi bakteri sama dengan kekeruhan suspensi standar berarti bakteri $10^{8} \mathrm{CFU} / \mathrm{mL}$.

\subsubsection{Pembiakan Bakteri}

1. Pembuatan Stok Kultur Bakteri

Satu ose kuman Streptococcus mutans diambil dengan memakai jarum ose steril kemudian ditambahkan pada media nutrient supaya miring dengan metode menggoreskan, sehabis itu diinkubasi dalam inkubator pada temperatur 35- 370 sepanjang 18- 24 jam( Ditjen POM, 2014).

2. Pembuatan Inokulum Bakteri

Dari stok kultur kuman Streptococcus mutans yang sudah berkembang diambil dengan jarum ose steril kemudian disuspensikan dalam tabung yang berisi $10 \mathrm{ml}$ larutan nutrient broth, diukur kekeruhan larutan( Ditjen POM, 2014).

3. Pembuatan Larutan Uji Sediaan Pasta Gigi

Ditimbang Pasta gigi 1 gram dengan neraca analitik secara seksama buat FI, FII, FIII, FIV kemudian dilarutkan dengan pelarut DMSO sebanyak $1 \mathrm{ml}$ ke masing- masing perumusan serta dimasukkan kertas cakram ke masingmasing larutan resep sepanjang 15 menit.

4. Uji kegiatan antibakteri

Uji mikrobiologi buat mengenali kegiatan antibakteri yang dicoba dengan tata cara difusi memakai kertas cakram. Medium NA dituang ke cangkir petri sebanyak $10 \mathrm{ml}$, setelah itu kuman Streptococcus mutans selaku biakan uji dipipet dari medium ke 
cangkir petri steril sebanyak $10 \mu l$, cangkir petri setelah itu digoyang secara lambat- laun buat menyebarkan kuman secara menyeluruh serta didiamkan sampai medium memadat. Tiap- tiap dari kertas cakram steril dipindahkan secara aseptik memakai pingset steril dalam ketiga larutan uji serta direndam \pm 1 menit. Setelah itu pindahkan dengan pinset steril ke medium NA yang telah berisi Streptococcus mutans secara aseptik, kemudian diinkubasi sepanjang $1 \times 24$ jam dalam temperatur 370. Sehabis diinkubasi diamati zona bening yang ada disekitar kertas cakram serta diukur diamaternya memakai jangka sorong.

\section{Hasil Dan Pembahasan}

Hasil skrining fitokimia ekstrak daun pandan wangi mengandung

Tabel 3. Hasil Uji Organoleptis

$\begin{array}{lll}\text { Formul } & \text { Parame } & \text { Hari ke - } \\ \text { a } & \text { ter }\end{array}$

senyawa flavonoid, alkaloid, saponin, tanin, fenol dan steroid. Sediaan gel pasta gigi yang telah dibuat dan di uji organoleptis dapat dilihat pada tabel 3 .

Tabel 3 Hasil uji homogenitas dapat dilihat pada sediaan menunjukkan bahwa sediaan homogen secara fisik yang menandakan bahan sediaan gel pasta gigi tercampur merata.

Hasil uji pH pada F1 dan F2 memiliki $\mathrm{pH}$ 7-7,1 sedangkan pada F3 memiliki nilai $\mathrm{pH} 6,7$. Perbedaan nilai $\mathrm{pH}$ pada $\mathrm{F} 3$ yang lebih asam dikarenakan ekstrak yang ditambahkan lebih banyak dengan nilai $\mathrm{pH}$ ekstrak yaitu 3.

\begin{tabular}{|c|c|c|c|c|c|}
\hline & & 0 & 7 & 14 & 21 \\
\hline 1 & $\begin{array}{l}\text { Bau } \\
\text { Warna } \\
\text { Bentuk }\end{array}$ & $\begin{array}{l}\text { Khas pandan } \\
\text { Warna Hijau } \\
\text { Gel }\end{array}$ & $\begin{array}{l}\text { Khas pandan } \\
\text { Warna Hijau } \\
\text { Gel }\end{array}$ & $\begin{array}{l}\text { Khas pandan } \\
\text { Warna Hijau } \\
\text { Gel }\end{array}$ & $\begin{array}{l}\text { Khas pandan } \\
\text { Warna Hijau } \\
\text { Gel }\end{array}$ \\
\hline 2 & $\begin{array}{l}\text { Bau } \\
\text { Warna } \\
\text { Bentuk }\end{array}$ & $\begin{array}{l}\text { Khas pandan } \\
\text { Warna Hijau } \\
\text { agak Tua } \\
\text { Gel }\end{array}$ & $\begin{array}{l}\text { Khas pandan } \\
\text { Warna Hijau } \\
\text { agak Tua } \\
\text { Gel }\end{array}$ & $\begin{array}{lr}\text { Khas } & \text { pandan } \\
\text { Warna } & \text { Hijau } \\
\text { agak Tua } & \\
\text { Gel } & \end{array}$ & $\begin{array}{lr}\text { Khas } & \text { pandan } \\
\text { Warna } & \text { Hijau } \\
\text { agak Tua } & \\
\text { Gel } & \end{array}$ \\
\hline 3 & $\begin{array}{l}\text { Bau } \\
\text { Warna } \\
\text { Bentuk }\end{array}$ & $\begin{array}{l}\text { Khas pandan } \\
\text { Warna Hijau } \\
\text { Tua } \\
\text { Gel }\end{array}$ & $\begin{array}{l}\text { Khas pandan } \\
\text { Warna Hijau } \\
\text { Tua } \\
\text { Gel }\end{array}$ & $\begin{array}{lr}\text { Khas } & \text { pandan } \\
\text { Warna } & \text { Hijau } \\
\text { Tua } & \\
\text { Gel } & \\
\end{array}$ & $\begin{array}{lr}\text { Khas } & \text { pandan } \\
\text { Warna } & \text { Hijau } \\
\text { Tua } & \\
\text { Gel } & \\
\end{array}$ \\
\hline
\end{tabular}

Dari uji daya sebar F1 diperoleh

$5,1 \mathrm{~cm} ; \mathrm{F} 2$ diperoleh $5,2 \mathrm{~cm}$ dan F3 diperoleh $6 \mathrm{~cm}$. Dari ketiga formula yang diuji rata-rata memiliki nilai daya sebar yang baik karena memenuhi persyaratan daya sebar yaitu $5-7 \mathrm{~cm}$. Daya sebar sediaan semakin besar maka nilai viskositas sediaan semakin rendah (Pratiwi, 2016).

Tujuan dilakukan pengujian daya lekat yaitu untuk mengetahui seberapa cepat sediaan melekat kekulit atau alat gosok gigi. Masing-masing formula memiliki rata-rata daya lekat yang berbeda disebabkan karena perbedaan viskositas yaitu pada F1 sebesar 7,54, pada F2 sebesar 6,08 dan pada F3 sebesar 4,33. Hal ini dipengaruhi oleh viskositasnya, semakin besar viskositas maka perlekatan semakin lama. 
Received: 22 December 2021 :: Accepted: 29 December 2021 :: Published: 05 January 2021

Uji viskositas dilakukan untuk mengetahui mudah tidaknya sediaan dikeluarkan dari tube, semakin rendah nilai viskositasnya maka semakin mudah sediaan dikeluarkan. Dari hasil uji viskositas diperoleh data dari viskositas $\mathrm{F} 1$ pada hari ke-0 adalah 1810 dPa-s dan pada hari ke-7 sampai hari ke-21 adalah 1809 dPas, viskositas F2 pada hari ke-0 adalah 1789 dPa-s dan pada hari ke-7 sampai hari ke-21 adalah 1788 dPa-s sedangkan viskositas F3 pada hari ke-0 adalah 1771 dPa-s dan pada hari ke-7 sampai hari ke-21 adalah 1769 dPa-s. Nilai viskositas F1 lebih besar dari viskositas F2 dan F3 dikarenakan perbedaan konsentrasi ekstrak daun pandan wangi (Pandanus amaryllifolius Roxb.).

Hasil uji pH freeze-thaw cycling sesudah maupun sebelum mengalami suhu ekstrim selama 3 siklus nilai $\mathrm{pH}$ pada $\mathrm{F} 1$ yaitu 7,1 , nilai $\mathrm{pH}$ F2 yaitu 7,0 dan nilai $\mathrm{pH} \mathrm{F} 3$ yaitu 6,7 .

Hasil Uji Viskositas Freezethaw cycling seudah maupun sebelum mengalami suhu ekstrim selama 3 siklus setiap siklusnya mengalami penurunan dikarenakan selama 3 siklus mengalami kenaikan dan penurunan suhu yang mengakibatkan sediaan tidak stabil akan tetapi hasil viskositas masih dalam rentang.

\section{Kesimpulan}

Ekstrak daun pandan wangi (Pandanus amaryllifolius Roxb.) dapat diformulasikan ke dalam sediaan gel pasta gigi yang stabil dan memenuhi persyaratan meliputi uji organoleptis, uji pH, uji homogenitas, uji daya sebar, uji daya lekat, viskositas dan uji freezethaw cycling.

\section{Ucapan Terimakasih}

Ucapan terima kasih disampaikan kepada lembaga yang membantu pendanaan dalam melaksanakan proses pengabdian masyarakat.

\section{Daftar Pustaka}

Dasopang E.S dan Simutuah A (2016). Formulas Sediaan Gel Antiseptik Tangan Dan Uji Antibakteri Dari Ekstrak Etanol Daun Pandan Wangi(Pandanus amaryllifolius Roxb.). BioLink Vol.3(1): 81-91

Fatmala R (2018). Formulasi Sediaan Pasta Gigi Gel Ekstrak Kulit Buah Nanas (Ananas comosusL.Merr). Prodi Farmasi Sekolah Tinggi Ilmu Kesehatan Muhammadiyah Pekajangan Pekalongan.

Fulviana Maulia. (2013). Formulasi Sediaan Gel Antibakteri Ekstrak Etanol Herba Patikan Kebo (Euohorbia hirta L.) Dan Uji Aktivitas Secara In-Vitro Terhadap Pseudomonas aeruginosa. Fakultas Farmasi Universitas Muhammadiyah Surakarta.

Hanani Endang (2016). Analisis Fitokimia. Jakarta : EGC

Hidayat R dan Tandiari A (2016). Kesehatan Gigi Dan Mulut Edisi I. Yogyakarta.

Rahmadhan, Ardyan Gilang (2010). Serba Serbi Kesehatan Gigi Dan Mulut. Penyunting Natalia Putr Handayani. Jakarta: bukune

Rahman Dea Arditia (2009). Optimasi Formula Gel Gigi Mengandung Ekstrak Daun Jambu Biji (Psidium guajavaL.) Dengan $\mathrm{Na} \mathrm{CMC}$ Sebagail Gelling Agent. Skripsi. Jakarta. Program Studi Farmasi Fakultas Kedokteran Dan Ilmu Kesehatan Universitas Islam Negeri (UIN) Syarif Hidayatullah. 